\title{
Gene Expression o Endocannabinoid System Components in Skeletal Muscle and Adipose Tissue of South Asians and White Caucasians with Overweight
}

Citation for published version (APA):

Nahon, K. J., Kantae, V., den Haan, R., Hanssen, M. J. W., Harms, A. C., van der Stelt, M., Hankemeier, T., Jazet, I. M., van Marken Lichtenbelt, W. D., Rensen, P. C. N., \& Boon, M. R. (2018). Gene Expression o Endocannabinoid System Components in Skeletal Muscle and Adipose Tissue of South Asians and White Caucasians with Overweight. Obesity, 26(8), 1332-1337. https://doi.org/10.1002/oby.22245

Document status and date:

Published: 01/08/2018

DOI:

10.1002/oby.22245

Document Version:

Publisher's PDF, also known as Version of record

Document license:

Taverne

Please check the document version of this publication:

- A submitted manuscript is the version of the article upon submission and before peer-review. There can be important differences between the submitted version and the official published version of record.

People interested in the research are advised to contact the author for the final version of the publication, or visit the DOI to the publisher's website.

- The final author version and the galley proof are versions of the publication after peer review.

- The final published version features the final layout of the paper including the volume, issue and page numbers.

Link to publication

\footnotetext{
General rights rights.

- You may freely distribute the URL identifying the publication in the public portal. please follow below link for the End User Agreement:

www.umlib.nl/taverne-license

Take down policy

If you believe that this document breaches copyright please contact us at:

repository@maastrichtuniversity.nl

providing details and we will investigate your claim.
}

Copyright and moral rights for the publications made accessible in the public portal are retained by the authors and/or other copyright owners and it is a condition of accessing publications that users recognise and abide by the legal requirements associated with these

- Users may download and print one copy of any publication from the public portal for the purpose of private study or research.

- You may not further distribute the material or use it for any profit-making activity or commercial gain

If the publication is distributed under the terms of Article 25fa of the Dutch Copyright Act, indicated by the "Taverne" license above, 


\title{
Gene Expression of Endocannabinoid System Components in Skeletal Muscle and Adipose Tissue of South Asians and White Caucasians with Overweight
}

\author{
Kimberly J. Nahon (D) 1,2*, Vasudev Kantae (D) 3*, Roy den Haan ${ }^{1,2}$, Mark J.W. Hanssen ${ }^{4}$, Amy C. Harms ${ }^{3}$, \\ Mario van der Stelt ${ }^{5}$, Thomas Hankemeier ${ }^{3}$, Ingrid M. Jazet ${ }^{1,2}$, Wouter D. van Marken Lichtenbelt ${ }^{4}$, \\ Patrick C.N. Rensen ${ }^{1,2}$ and Mariëtte R. Boon ${ }^{1,2}$
}

Objective: The study aimed to investigate whether markers of endocannabinoid signaling differed between overweight men of South Asian and white Caucasian descent.

Methods: We included South Asian $(n=10)$ and white Caucasian $(n=10)$ men with overweight and prediabetes aged 35 to 50 years. Plasma samples were analyzed for endocannabinoids, their congeners, and lipids. In white adipose tissue and skeletal muscle biopsies, mRNA expression of genes involved in the endocannabinoid system was assessed using quantitative RT-PCR. Fasting lipid oxidation and glucose oxidation were determined with indirect calorimetry.

Results: Compared with white Caucasians, South Asians had higher levels of plasma 2-linoleoyl glycerol $(P<0.01)$ and $N$-linoleoylethanolamine $(P<0.05)$. Interestingly, in skeletal muscle of South Asians, gene expression of cannabinoid receptors $\mathrm{CB}_{1}$ and $\mathrm{CB}_{2}$ was 10 -fold lower $(P<0.001)$ and that of the endocannabinoid degradation enzyme fatty acid amide hydrolase $2(F A A H 2)$ was 5 -fold lower $(P<0.001)$ compared with white Caucasians. Expression of genes involved in the endocannabinoid system in white adipose tissue was not different between the two ethnicities. After pooling of both ethnicities, plasma 2-arachidonoylglycerol (2-AG) positively correlated with plasma triglycerides $(R=0.77, P<0.001)$ and lipid oxidation $(R=0.55, P<0.05)$. Conclusions: Overweight South Asian men have higher plasma 2-linoleoyl glycerol and $N$-linoleoylethanolamine levels and lower gene expression of $\mathrm{CB}$ receptors and the endocannabinoid degradation enzyme FAAH2 in skeletal muscle compared with white Caucasians.

Obesity (2018) 26, 1332-1337. doi:10.1002/oby.22245

\section{Introduction}

The prevalence of obesity and related diseases, such as type 2 diabetes (T2D), is rapidly increasing worldwide. Particularly in South Asians, constituting nearly one-fourth of the world's population (1), an unfavorable metabolic profile consisting of obesity, dyslipidemia, and T2D is highly prevalent (2). Moreover, South Asians have a higher risk of developing cardiovascular disease, resulting in high morbidity and mortality (3). It is generally thought that the increased susceptibility to metabolic disease of South Asians might be due to a disturbed energy metabolism (4).

\footnotetext{
${ }^{1}$ Department of Medicine, Division of Endocrinology Leiden University Medical Center, Leiden, the Netherlands; ${ }^{2}$ Einthoven Laboratory for Experimental Vascular Medicine, Leiden University Medical Center, Leiden, the Netherlands; ${ }^{3}$ Division of Systems Biomedicine and Pharmacology, Leiden Academic Center for Drug Research, Leiden University, Leiden, the Netherlands; ${ }^{4}$ Department of Human Biology \& Human Movement Sciences, School of Nutrition and Translational Research in Metabolism, Maastricht University Medical Center, Maastricht, the Netherlands; ${ }^{5}$ Department of Molecular Physiology, Leiden Institute of Chemistry, Leiden University, Leiden, the Netherlands
}

\footnotetext{
Funding agencies: MRB is supported by a Netherlands Organization for Scientific Research (Grant 825.13.021) and by a Dutch Diabetes Research Foundation (Grant 2015.81.1808). Netherlands Heart Foundation (Grant 2009T038). This project received support from the Leiden University.

Disclosure: The authors declare no conflict of interest.

Author contributions: KJN and VK analyzed the data, wrote the manuscript, and contributed to the discussion. VK developed and validated the liquid chromatography coupled with tandem mass spectrometry (LC-MS/MS) method to quantify endocannabinoids, $N$-acylethanolamines, and arachidonic acid. ACH performed the LC-MS/MS and reviewed/edited the manuscript. RH analyzed the data, contributed to the discussion, and reviewed/edited the manuscript. MJWH and WDM designed the study and reviewed/edited the manuscript. MvdS, TH, IMJ, MRB, and PCNR designed the study, contributed to the discussion, and reviewed/edited the manuscript. Clinical trial registration: ClinicalTrials.gov identifier NCT02291458.

${ }^{1}$ Kimberly J. Nahon and Vasudev Kantae contributed equally to this work.
} 
The endocannabinoid system (ECS) is involved in maintaining energy balance by impacting on energy intake and expenditure as well as lipolysis (5). The ECS is present both centrally and in peripheral metabolic tissues, including the liver, pancreas, skeletal muscle, white adipose tissue (WAT), and brown adipose tissue (6). In skeletal muscle, endocannabinoids reduce glucose uptake and oxidative pathways $(7,8)$, thereby reducing energy expenditure. In WAT, endocannabinoids stimulate energy storage by increasing lipogenesis and adipogenesis $(5,9,10)$. Thus, endocannabinoid stimulation of skeletal muscle and WAT collectively results in a positive energy balance.

The ECS consists of $\mathrm{G}$ protein-coupled cannabinoid receptors (i.e., type 1 and type $2\left[\mathrm{CB}_{1}\right.$ and $\left.\mathrm{CB}_{2}\right]$ ), the endogenous lipid ligands (endocannabinoids), and the enzymatic machinery for their synthesis and degradation. Anandamide (AEA) and 2-arachidonoylglycerol (2-AG) are the most studied endocannabinoids and are synthesized on demand from their membrane lipids through the action of the biosynthetic enzymes $N$-acyl-phosphatidylethanolamine phospholipase D and diacylglycerol lipase (DAGL), respectively. Endocannabinoids are degraded by specific enzymes. Fatty acid amide hydrolase (FAAH1 and FAAH2) inactivates AEA, and monoglyceride lipase hydrolyzes 2-AG. Arachidonic acid is a precursor molecule and metabolite for endocannabinoids. AEA belongs to a family of bioactive $N$-acylethanolamines, which include $N$-linoleoylethanolamine, $N$-palmitoylethanolamine, $\mathrm{N}$-oleoylethanolamine, $\mathrm{N}$-stearoylethanolamine, and $\mathrm{N}$-docosatetraenylethanolamide. These $N$-acylethanolamines arise from the same biosynthetic pathway as AEA and are capable of indirectly modulating cannabinoid receptor activity by interfering with endocannabinoid metabolism, which is known as an "entourage effect" (11). Palmitoylethanolamine and, especially, $N$-oleoylethanolamine interact with nuclear receptor peroxisome proliferator-activated receptor $\alpha$, stimulate lipolysis in the liver and adipocytes, and act as a satiety factor $(9,12)$.

We previously showed that young, healthy, lean South Asian men had lower resting energy expenditure (13) and higher circulating endocannabinoid levels compared with matched white Caucasians (14). High plasma endocannabinoid levels are associated with obesity (15) and T2D (6) and affect peripheral metabolic organs, including adipose tissue and skeletal muscle (5). In addition, individuals with obesity have reduced gene expression of endocannabinoid degradation enzymes and $\mathrm{CB}_{1}$ receptor in adipose tissue $(16,17)$. Elevated circulating endocannabinoid levels might be a result of decreased enzymatic degradation (16). As little is known about ECS in South Asian compared with white Caucasian men with overweight and prediabetes, we investigated circulating endocannabinoid levels and gene expression of $\mathrm{CB}$ receptors and enzymes involved in endocannabinoid synthesis and degradation in WAT and skeletal muscle of middle-aged men of South Asian and white Caucasian descent. We hypothesized that South Asian men with overweight and prediabetes would have elevated plasma endocannabinoid levels and consequently lower gene expression of $\mathrm{CB}$ receptors on peripheral tissues compared with Caucasian men with overweight and prediabetes.

\section{Methods}

\section{Ethics}

Blood and tissue samples were collected as part of a previously conducted crossover study to investigate the effect of L-arginine on brown adipose tissue activity and resting energy expenditure in South Asian and white Caucasian men with overweight and prediabetes (18) (ClinicalTrials.gov identifier NCT02291458, registered November 14, 2014). This study was approved by the Ethics Committee of Maastricht University Medical Center and the Leiden University Medical Center (LUMC) and undertaken in accordance with the principles of the revised Declaration of Helsinki. All volunteers provided written informed consent.

\section{Participants and study design}

In total, 20 Dutch men with prediabetes and overweight (BMI $\left.25-35 \mathrm{~kg} / \mathrm{m}^{2}\right)$ of South Asian $(n=10)$ and white Caucasian $(n=10)$ descent (aged 35-55 years) were enrolled. South Asians and white Caucasians were matched for BMI. This study was conducted at the LUMC (the Netherlands) between November 2014 and August 2015 (18). Subjects underwent medical screening including an oral glucose tolerance test to identify individuals with impaired glucose tolerance according to the American Diabetes Association 2010 (19) and/or World Health Organization criteria. In line with the American Diabetes Association criteria (19), prediabetes was defined as having either fasting plasma glucose levels between 5.6 and $6.9 \mathrm{mmol} / \mathrm{L}$ or plasma glucose levels 2 hours after an oral glucose tolerance test between 7.8 and $11.1 \mathrm{mmol} / \mathrm{L}$. Exclusion criteria included the presence of chronic disease, including T2D, smoking, and recent body weight change up to 3 months prior to the start of the study.

\section{Study procedures}

The study procedures were described previously (18). In short, subjects were treated for 6 weeks with either L-arginine $(9 \mathrm{~g} / \mathrm{d})$ (Argimax; Hankintatukku Oy, Karkkila, Finland) or placebo supplements (containing 70\% microcrystalline cellulose, 29\% maize starch, and 1\% magnesium stearate) in a randomized double-blind crossover design, with a 4 -week washout period. Each treatment period was followed by two consecutive study days, which consisted of several measurements. During the first study day, lipid oxidation and glucose oxidation were determined for 30 minutes with indirect calorimetry using a face mask (EZcal; IDEE, Maastricht Instruments, Maastricht, the Netherlands), and subsequently fasted venous blood samples were collected to quantify plasma triglycerides (using commercially available enzymatic colorimetric kits and an ABX Pentra 400 autoanalyzer; Horiba, Montpellier, France) and endocannabinoids (liquid chromatography coupled with tandem mass spectrometry [LC-MS/ MS]) as described previously (14). The next day, fasted WAT (abdominal subcutaneous adipose tissue) and skeletal muscle (vastus lateralis) biopsies were collected as described previously (20). The tissues were instantly placed in ice-cold preservation medium (BIOPS; OROBOROS Instruments, Innsbruck, Austria) and stored at $-80^{\circ} \mathrm{C}$. Thereafter, body composition was determined by means of dual x-ray absorptiometry (Discovery A; Hologic, Bedford, Massachusetts). From one white Caucasian, no dual x-ray absorptiometry scan data were available because of technical problems. For the purpose of this study, only the fasted blood samples and WAT and skeletal muscle biopsies taken after placebo treatment were analyzed. All samples were taken at the same time of the day in all volunteers. Blood samples were obtained during the first study day at 11 Am after a 4-hour fast. WAT and skeletal muscle biopsies were obtained during the second study day at $8 \mathrm{Am}$ after an overnight fast. 


\section{Endocannabinoid measurements}

Plasma endocannabinoids and their congeners were quantified with LC-MS/MS. From the pool of individual study samples, quality controls were used to generate calibration curves. Additionally, all samples were randomized, and each batch included calibration samples and an even distribution of quality control samples and blanks. The sample extraction procedure and method are as described in detail previously (14).

\section{WAT and skeletal muscle gene expression}

WAT and skeletal muscle biopsies of South Asians and white Caucasians after placebo treatment were analyzed. RNA was extracted using TriPure Isolation Reagent (Roche, Molecular Biochemicals, Indianapolis, Indiana). Total RNA was reversetranscribed using Promega M1705 reverse transcriptase for reverse-transcription polymerase chain reaction (PCR) (Promega, Leiden, the Netherlands) according to the instructions by the manufacturer to produce complementary DNA. Gene expression levels of enzymes involved in endocannabinoid synthesis (DAGLA and DAGLB, NAPEPLD, and PLA2G4E) and degradation (MGLL, FAAH1, and $F A A H 2)$ and $C B$ receptors (CNRI and $C N R 2$ ) were determined in a 96-well PCR plate by real-time PCR (Bio-Rad CFX96; Bio-Rad, Veenendaal, the Netherlands), using gene-specific primers (Table 1) and iQ SYBR Green Supermix (Bio-Rad). For analysis and quantification, Bio-Rad CFX Manager software version 3.1 was used. Gene expression was normalized by using $18 S$ (for WAT) or GAPDH (for skeletal muscle) mRNA content and expressed as fold difference compared with white Caucasians using the $\Delta \Delta \mathrm{CT}$ method.

\section{Statistical analysis}

Data were collected and analyzed using SPSS Statistics version 23.0 (IBM Corp., Armonk, New York). Baseline characteristics and differences in plasma endocannabinoid levels between ethnicities were compared using unpaired Student $t$ tests. Furthermore, linear regression analysis computed by Pearson correlation was used to determine correlations between plasma endocannabinoid levels and different metabolic parameters. Regression analysis was performed both with and without correction for the effect of ethnicity, by respectively including/excluding ethnicity as a covariate. $P$ values $<0.05$ were considered statistically significant. Data are presented as mean \pm SEM.

\section{Results}

\section{Clinical characteristics}

The clinical characteristics of the participants were partly described previously (18). In brief, 20 men with overweight and prediabetes of South Asian $(n=10)$ and white Caucasian $(n=10)$ descent were included. Mean age $(46.5 \pm 2.8$ vs. $47.5 \pm 2.0$ years $)$ and BMI $(30.1 \pm 1.1$ vs. $30.7 \pm 1.2)$ were comparable between South Asians and white Caucasians, respectively, as were body fat percentage $(31.0 \pm 1.1 \%$ vs. $30.1 \pm 1.0 \%)$, plasma triglyceride concentration $(1.6 \pm 0.2$ vs. $1.5 \pm 0.2 \mathrm{mmol} / \mathrm{L})$, and fasting glucose level $(5.6 \pm 0.5$ vs. $5.7 \pm 0.7 \mathrm{mmol} / \mathrm{L})$. Resting energy expenditure was lower in South Asians as compared with white Caucasians

\begin{tabular}{|c|c|c|}
\hline Gene & Forward primer & Reverse primer \\
\hline $18 S$ & AGGATCCATTGGAGGGCAAGT & TCCAACTACGAGCTTTTTAACTGCA \\
\hline CNR1 & GATGTACTTGCCCTGACCATA & AACATTCTAGGACTGATTCATCATG \\
\hline CNR2 & AAGATTGGCAGCGTGACTATG & CAGGCAGAGGTATCGGTCAA \\
\hline$D A G L A$ & ССАТСТТССТСТTТСТССТ & CTCGTGCGGGTTATAGAC \\
\hline$D A G L B$ & GTCTTCCCAGGGTTCTTC & TGAGGACGATCAAGTAAC \\
\hline FAAH1 & GGGCCGTCAGCTACACTATGC & ATGTTCCATCTGGGCCTCGTC \\
\hline FAAH2 & CGCTAGGCTTTCTCATAGGC & CCGAAAGCAGAAGCAATGGTT \\
\hline GAPDH & TTGCAGGAGCGAGATCCCT & CACCCATGACGAACATGGG \\
\hline MGLL & TCTTCCTTCTGGGCCACTCCA & GGATTGGCAAGAACCAGAGG \\
\hline NAPEPLD & СССТCTATTCCAAATGTTCT & CATCCATTTCCACCATTAC \\
\hline PLA2G4E & GAGCCCACAAACGGATGAAG & GTCTGTCTGGCTCAGCATATCA \\
\hline
\end{tabular}

( $4.9 \pm 0.2$ vs. $5.7 \pm 0.2 \mathrm{~kJ} / \mathrm{min}, P<0.05)$, whereas lipid and glucose oxidation did not differ significantly.

\section{South Asians have higher plasma levels of some endocannabinoids}

First, we studied circulating endocannabinoid levels in both ethnicities. Plasma 2-AG and AEA levels were comparable between South Asians and white Caucasians (12.8 \pm 1.5 vs. $10.6 \pm 1.2 \mathrm{pmol} /$ $\mathrm{mL}$, Figure $1 \mathrm{~A}$, and $1.0 \pm 0.1$ vs. $0.9 \pm 0.1 \mathrm{pmol} / \mathrm{mL}$, Figure $1 \mathrm{~B}$, respectively). Plasma arachidonic acid tended to be higher in South Asians (18.3 \pm 1.1 vs. $14.6 \pm 1.6 \mathrm{nmol} / \mathrm{mL}, P=0.07$; Figure $1 \mathrm{C})$. In addition, plasma 2-linoleoyl glycerol $(208 \pm 23$ vs. $114 \pm 17 \mathrm{pmol} /$ $\mathrm{mL}, P<0.01$; Figure 1D) and $N$-linoleoylethanolamine $(3.0 \pm 0.2$ vs. $2.2 \pm 0.2 \mathrm{pmol} / \mathrm{mL}, P<0.05$; Figure $1 \mathrm{E})$ were higher in South Asians compared with white Caucasians. Plasma 1-linoleoyl glycerol $(243 \pm 28$ vs. $169 \pm 30 \mathrm{pmol} / \mathrm{mL}, \quad P=0.09$; Supporting Information Table $\mathrm{S} 1$ ) and $N$-docosatetraenylethanolamide $(6.3 \pm 0.4$ vs. $5.3 \pm 0.4 \mathrm{pmol} / \mathrm{mL}, P=0.08$; Supporting Information Table S1) both tended to be higher in South Asians. No significant differences were observed for other $N$-acylethanolamines and mono- and di-acyl glycerols measured.

\section{Circulating endocannabinoid levels correlate with plasma triglycerides and lipid oxidation}

We next investigated whether circulating endocannabinoid levels correlated with metabolic parameters in our study by pooling endocannabinoid levels of the two ethnicities. Plasma 2-AG levels positively correlated with plasma triglyceride levels $(R=0.77, P<0.001$; Figure 2A) and lipid oxidation $(R=0.55, P<0.05$; Figure $2 \mathrm{~B})$. In contrast, AEA levels did not correlate with any of these parameters (data not shown). To test whether the effects could be attributed to ethnicity, we repeated the regression analysis including ethnicity as a covariate and found that this did not change the results.

\section{South Asians have lower mRNA expression of $\mathrm{CB}$ receptors and endocannabinoid degradation enzymes in skeletal muscle}

Because circulating endocannabinoid levels do not necessarily reflect tissue-specific signaling, we next assessed mRNA expression of $\mathrm{CB}$ receptors and enzymes involved in endocannabinoid 

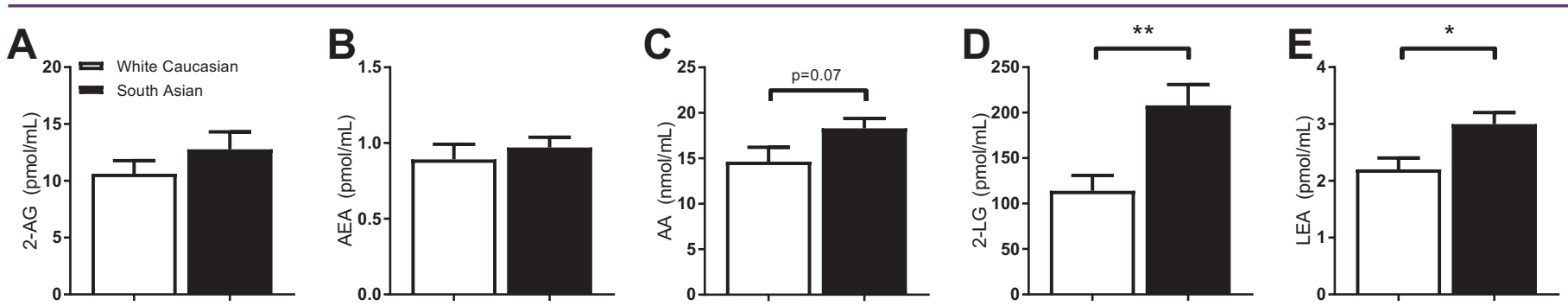

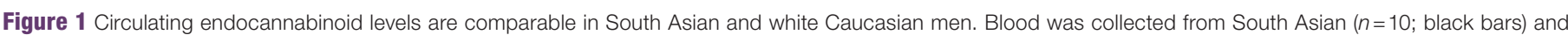

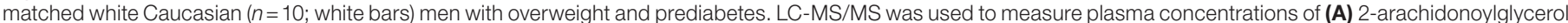

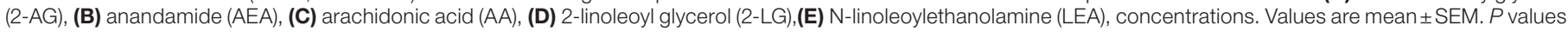
are based on unpaired $t$ tests. ${ }^{\star} P<0.05,{ }^{\star \star} P<0.01$

synthesis and degradation in WAT and skeletal muscle biopsies of South Asian and white Caucasian men.

In WAT, expression levels of all measured genes were not different between the two ethnicities (Figure 3A). However, in skeletal muscle, the relative expression of the degradation enzyme FAAH2 (FAAH2) was fivefold lower in South Asians compared with white Caucasians $(-81 \%, P<0.001$; Figure $3 \mathrm{~B})$. In addition, expression of the other degradation enzymes, monoglyceride lipase $(M G L L)$ and FAAH1 $(F A A H 1)$, tended to be lower in South Asians $(-22 \%$, $P=0.05$ and $-18 \%, P=0.07$, respectively; Figure 3B). Moreover, expression of both the $\mathrm{CB}_{1}(C N R 1)$ and $\mathrm{CB}_{2}(C N R 2)$ receptor was approximately 10-fold lower in South Asians as compared with white Caucasians $(-93 \%, P<0.001$ and $-90 \%, P<0.001$; Figure $3 B$ ). Expression of endocannabinoid synthesis enzymes was comparable (Figure 3B) between the two ethnicities.

\section{Discussion}

The incidence of obesity and T2D is particularly high in individuals of South Asian descent. In the present study, we investigated different markers of endocannabinoid signaling in South Asian and white
Caucasian men with overweight and prediabetes. Here we report that plasma 2-linoleoyl glycerol and $N$-linoleoylethanolamine were higher in South Asians compared with white Caucasians. In addition, gene expression of the enzymes involved in endocannabinoid degradation as well as $\mathrm{CB}$ receptors in skeletal muscle was markedly lower in South Asians as compared with white Caucasians. In addition, plasma 2-AG correlated positively with plasma triglycerides and lipid oxidation.

We observed higher levels of the endocannabinoids 2-linoleoyl glycerol and $N$-linoleoylethanolamine in South Asian compared with white Caucasian men with overweight and prediabetes. In our previous study in healthy lean South Asians and white Caucasians, we also observed higher endocannabinoid levels in South Asians; however, in that study, other endocannabinoids (i.e., 2-AG and AEA) were higher (14). If we compare the effect sizes between the two different cohorts, we observe that except for $N$-palmitoylethanolamide, all effects are in the same direction, albeit that the effect sizes differ for most endocannabinoids between the two cohorts. Furthermore, there is no clear pattern in the effect size with respect to whether it is larger in either the lean cohort or the cohort with overweight. This is likely due to the different phenotype of the subjects in both cohorts. Of note, circulating endocannabinoid
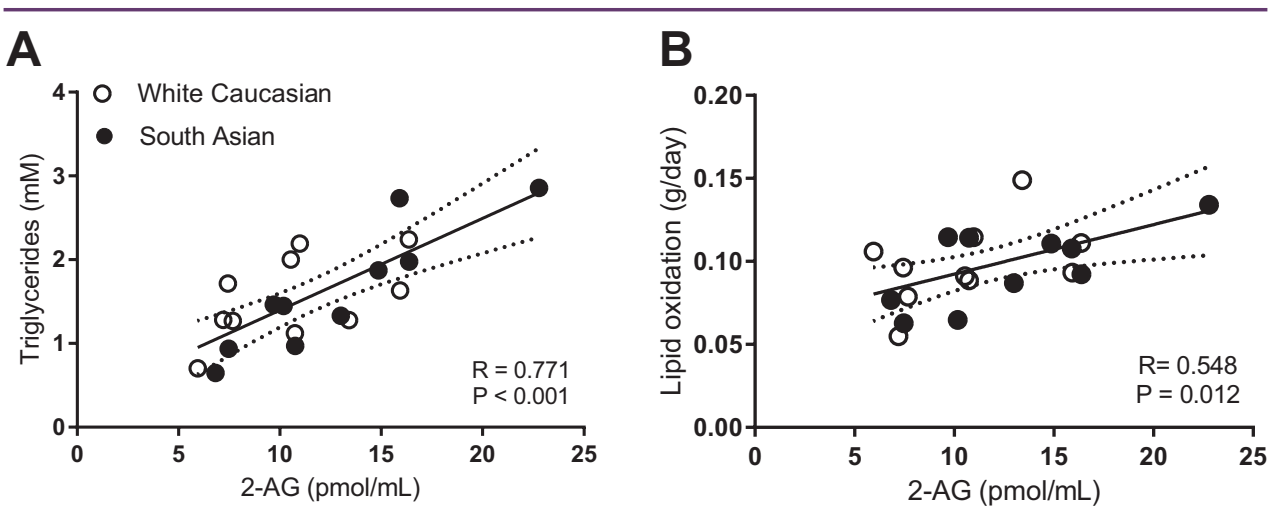

Figure 2 Plasma 2-arachidonoylglycerol (2-AG) levels positively correlate with plasma triglyceride levels and with lipid oxidation in South Asian and white Caucasian men. Scatterplot of the correlations between 2-AG levels and (A) plasma triglycerides or (B) lipid oxidation. Correlations are shown for the total group combined $(n=20)$; white circles represent white Caucasian men $(n=10)$, and black circles represent South Asian men $(n=10)$, with 95\% confidence limits. Correlations were analyzed using linear regression analysis. 

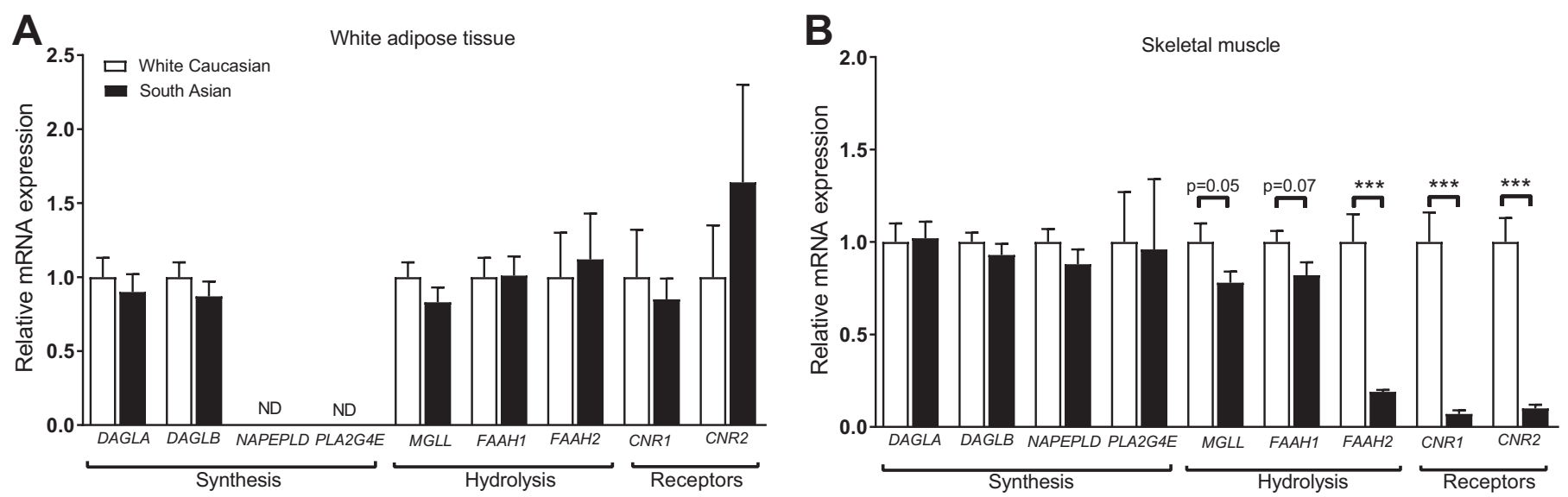





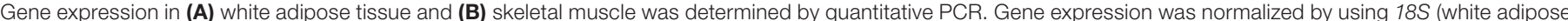


mean \pm SEM. $P$ values are based on an unpaired Student $t$ test. ${ }^{\star \star \star} P<0.001$. ND, not detectable.

levels in this cohort of men with overweight and prediabetes were not significantly higher compared with endocannabinoid levels measured in our previous cohort of healthy lean men. Probably, the difference in BMI between the two cohorts was insufficiently large (average BMI of 22 in lean men vs. 30 in overweight men) to observe differences in circulating endocannabinoid levels between the two cohorts.

We also found a strong correlation between 2-AG and plasma triglyceride levels. This correlation was also present in our previous cohort of healthy lean South Asian and white Caucasian men (14) and is in line with results of Bluher et al. (21). The biological explanation for this correlation is currently unknown. Possibly, it can at least partly be explained by the fact that both $2-\mathrm{AG}$ and triglycerides are lipid molecules with common lipid intermediates as precursors (e.g., diacylglycerol), resulting in production and secretion into blood of 2-AG concomitant with very low-density lipoprotein triglyceride.

To investigate potential differences in endocannabinoid signaling in metabolically active tissues, we examined WAT and skeletal muscle biopsies from these men with overweight and prediabetes. We did not observe differences in expression of genes involved in endocannabinoid signaling in WAT between the two ethnicities. Interestingly, in skeletal muscle, we found that mRNA expression of the endocannabinoid degradation enzymes and $\mathrm{CB}$ receptors was lower in South Asians as compared with white Caucasians. Possibly, low expression of degradation enzymes in skeletal muscle of the South Asian men might have contributed to higher local endocannabinoid levels within skeletal muscle, thereby possibly inducing $\mathrm{CB}$ receptor downregulation in this tissue (15). Alternatively, the dietary intake between South Asians and white Caucasians may have been different, as South Asian diets often contain low n-3 polyunsaturated fatty acids, which have been shown to modulate the expression of endocannabinoid synthesis and degradation enzymes and CB receptors (22). Although all subjects used a standardized meal the evening before the study day, we cannot exclude that differences in diet might have influenced our results. Based on our study, we can thus only speculate about the underlying mechanisms, which is an interesting subject of future studies. Interestingly, the CB1 receptor regulates metabolic processes, including insulin signaling, glucose uptake, and fatty acid oxidation in skeletal muscle $(7,8)$. Moreover, overstimulation of $\mathrm{CB}$ receptors in skeletal muscle can disrupt insulin signaling thereby promoting insulin resistance which could eventually lead to development of (pre)diabetes 5. Because South Asians are known to have an increased risk for the development of metabolic disease, including T2D 2, dysregulation of ECS in skeletal muscle might thus contribute to diabetes development in this population.

Our study has several limitations. First, we had a small sample size of 10 South Asian and 10 white Caucasian men. Secondly, all individuals were already metabolically deregulated as they had overweight and prediabetes. This may have limited the differences we could observe between the two ethnic groups. In addition, we can only speculate about the mechanisms underlying the differences in ECS signaling between South Asians and white Caucasians. Future studies in larger cohorts should investigate whether these results also apply to women and lean, non-prediabetic individuals to determine whether these results could be translated to the general population. A strength of our study is that we measured both circulating endocannabinoids and gene expression of the ECS in WAT and skeletal muscle in the same individuals.

Taken together, our data show that plasma 2-linoleoyl glycerol and $N$-linoleoylethanolamine were higher in South Asian compared with white Caucasian men with overweight and prediabetes. In addition, South Asian individuals had lower gene expression of enzymes involved in endocannabinoid degradation and $\mathrm{CB}$ receptors in skeletal muscle. Although it remains speculative, high endocannabinoid levels may deteriorate endocannabinoid signaling in metabolic organs, including skeletal muscle, and thereby may contribute to the development and/or progression of obesity and possibly even T2D, both of which are highly prevalent in South 
Asians. Further studies are required to show whether therapeutic interventions that target the ECS will improve the metabolic profile of these individuals. $\mathbf{O}$

\section{Acknowledgments}

The authors thank H. Sips (Department of Medicine, Division of Endocrinology, LUMC, Leiden) for her excellent technical support. The data sets generated during and/or analyzed during the current study are available from the corresponding author on reasonable request.

\section{(C) 2018 The Obesity Society}

\section{References}

1. Misra A, Shrivastava U. Obesity and dyslipidemia in South Asians. Nutrients 2013;5:2708-2733.

2. McKeigue PM, Shah B, Marmot MG. Relation of central obesity and insulin resistance with high diabetes prevalence and cardiovascular risk in South Asians. Lancet 1991;337:382-386.

3. Mather HM, Chaturvedi N, Fuller JH. Mortality and morbidity from diabetes in South Asians and Europeans: 11-year follow-up of the Southall Diabetes Survey, London, UK. Diabet Med 1998;15:53-59.

4. Hall LM, Moran CN, Milne GR, et al. Fat oxidation, fitness and skeletal muscle expression of oxidative/lipid metabolism genes in South Asians: implications for insulin resistance? PLoS One 2010;5:e14197. doi:10.1371/journal. pone. 0014197

5. Silvestri C, Ligresti A, Di Marzo V. Peripheral effects of the endocannabinoid system in energy homeostasis: adipose tissue, liver and skeletal muscle. Rev Endocr Metab Disord 2011;12:153-162.

6. Matias I, Gonthier MP, Petrosino S, et al. Role and regulation of acylethanolamides in energy balance: focus on adipocytes and beta-cells. Br J Pharmacol 2007:152:676-690.

7. Cavuoto P, McAinch AJ, Hatzinikolas G, Cameron-Smith D, Wittert GA Effects of cannabinoid receptors on skeletal muscle oxidative pathways. Mol Cell Endocrinol 2007;267:63-69.

8. Esposito I, Proto MC, Gazzerro P, et al. The cannabinoid CB1 receptor antagonist rimonabant stimulates 2-deoxyglucose uptake in skeletal muscle cells by regulating the expression of phosphatidylinositol-3-kinase. Mol Pharmacol 2008; $74: 1678-1686$.

9. Guzman M, Lo Verme J, Fu J, Oveisi F, Blazquez C, Piomelli D. Oleoylethanolamide stimulates lipolysis by activating the nuclear receptor peroxisome proliferator-activated receptor alpha (PPAR-alpha). JBiol Chem 2004;279:27849-27854.

10. van Eenige R, van der Stelt M, Rensen PCN, Kooijman S. Regulation of adipose tissue metabolism by the endocannabinoid system. Trends Endocrinol Metab 2018;29:326-337.

11. Ho WS, Barrett DA, Randall MD. "Entourage" effects of $N$-palmitoylethanolamide and $N$-oleoylethanolamide on vasorelaxation to anandamide occur through TRPV1 receptors. Br J Pharmacol 2008;155:837-846.

12. Schwartz GJ, Fu J, Astarita G, et al. The lipid messenger OEA links dietary fat intake to satiety. Cell Metab 2008;8:281-288.

13. Bakker LE, Boon MR, van der Linden RA, Arias-Bouda LP, et al. Brown adipose tissue volume in healthy lean South Asian adults compared with white Caucasians: a prospective, case-controlled observational study. Lancet Diabetes Endocrinol 2014;2:210-217.

14. Kantae V, Nahon KJ, Straat ME, et al. Endocannabinoid tone is higher in healthy lean South Asian than white Caucasian men. Sci Rep 2017;7:7558. doi:10.1038/s41598-017-07980-5

15. Engeli S. Dysregulation of the endocannabinoid system in obesity. JNeuroendocrinol 2008;20(suppl 1):110-115.

16. Engeli S, Bohnke J, Feldpausch M, et al. Activation of the peripheral endocannabinoid system in human obesity. Diabetes 2005;54:2838-2843.

17. Matias I, Gonthier MP, Orlando P, et al. Regulation, function, and dysregulation of endocannabinoids in models of adipose and beta-pancreatic cells and in obesity and hyperglycemia. JClin Endocrinol Metab 2006;91:3171-3180.

18. van Dam AD, Hanssen MJW, van Eenige R, et al. South Asian men have lower expression of IFN signalling genes in white adipose tissue and skeletal muscle compared with white men. Diabetologia 2017;60:2525-2528.

19. Chamberlain JJ, Rhinehart AS, Shaefer CF, Jr., Neuman A. Diagnosis and management of diabetes: synopsis of the 2016 American Diabetes Association Standards of Medical Care in Diabetes. Ann Intern Med 2016;164:542-552.

20. Bakker LE, van Schinkel LD, Guigas B, et al. A 5-day high-fat, high-calorie diet impairs insulin sensitivity in healthy, young South Asian men but not in Caucasian men. Diabetes 2014;63:248-258.

21. Bluher M, Engeli S, Kloting N, et al. Dysregulation of the peripheral and adipose tissue endocannabinoid system in human abdominal obesity. Diabetes 2006;55:3053-3060.

22. Hutchins-Wiese HL, Li Y, Hannon K, Watkins BA. Hind limb suspension and long-chain omega-3 PUFA increase mRNA endocannabinoid system levels in skeletal muscle. JNutr Biochem 2012;23:986-993. 